\title{
Analysis of A 220kV Current Transformer Explosion Accident
}

\author{
Zhu Yi, Rong Hua, Liu Xu, Ren Honggang, Wang Shimin, Wang Aimin, Wang \\ Hai, Wang Jia
}

Jinzhou Power Supply Company, Liaoning Electric Power Company Limited, State Grid, China

fushunpowersupply@163.com

Keywords: current transformer; fault analysis; power quality; harmonic voltage; flicker

\begin{abstract}
In this paper, the explosion accident of a $220 \mathrm{kV}$ current transformer in a $220 \mathrm{kV}$ substation is studied. It uses method of scene investigation and test to analyses the accident based on the principle and characteristics of current transformer. Through the analysis, this paper holds that reducing in main insulation electrical strength caused by Long-term high harmonic voltage and main insulation breakdown caused by flicker impact are main causes of the accident. And it also proposes a variety of management methods and technical measures to avoid this kind of accident. This paper provides a reference for the analysis of the same type of accident.
\end{abstract}

\section{Introduction}

As one of important equipments in power system, a current transformer is widely used in substations. Its main role is to provide a signal for power system measurement and relay protection. According to the kind of insulating medium, current transformers are divided for oil immersed current transformers, dry type current transformers and sulfur hexafluoride current transformers. Among them, oil immersed current transformers are widely used in $220 \mathrm{kV}$ power systems with fast heat dissipation, uniformity conduction and insulation recovery. Besides, simple structure, mature technology, reliable operation and low cost are advantages of current transformers. So, they are very important for power systems. Occurrences of accident of $220 \mathrm{kV}$ oil immersed current transformer will not only endanger the surrounding equipments, causing blackouts but also threaten the safety of operation personnel, resulting in very serious consequences. Therefore, the analysis of this type of accident is very important for current transformer technology supervision, and can provide favorable conditions for eliminating and reducing the occurrence of power system equipment failure[1-3].

\section{The structure of oil immersed current transformer}

At present, the main structure of the oil immersed current transformer in $220 \mathrm{kV}$ substation is oil immersed capacitor type structure. The primary winding is a " $U$ " type structure, and the main insulation is wrapped in it. The oil paper insulation is divided into a lot of insulating layers by the conductive or semi conductive electric layers, so each of the two electric layers with a dielectric layer is formed as a capacitor. Among the layers, the innermost one is connected with the primary winding, called the zero layer. And the outermost one is called the end capacitance layer[4,5].

\section{The introduction of the accident}

A blast happened to the B-phase current transformer of the $220 \mathrm{kV} \# 1$ transformer in a substation at 23:30 in one day in July 2015. The weather condition at that time was good, and there was no work there.

(1) The inspection of the accident scene

In the accident scene, it was found that the porcelain sleeve of the current transformer was blown to bits. The broken pieces showered around, and the farthest one is 100 meters away. Most parts of the current transformer were burnt only with the expander, the oil tank and the charred main capacitor left. Different degrees of damages were appeared in the Devices around. The condition is 
shown in Figure 1.

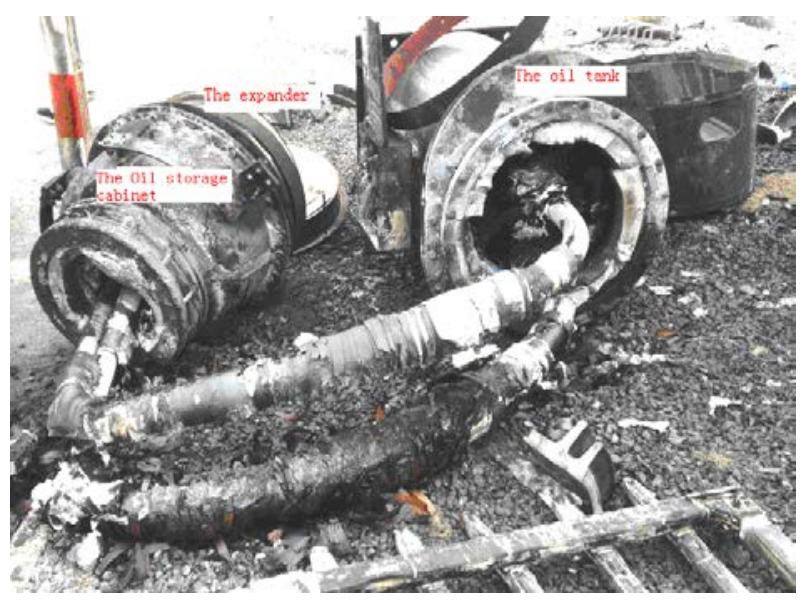

Fig.1 The accident scene

(2) The condition of the electrical test

The electrical test before commission of the current transformer was taken in November 1998, and results satisfied the relevant standards. Since running, it had gone well without any oil seepage phenomena. The results of every high voltage test and chromatographic Analysis satisfied the relevant requirements. Specific data is shown in Table 1 and Table 2.

Table 1 All previous high pressure tests data

\begin{tabular}{|l|l|l|l|l|l|l|l|}
\hline Date & $\begin{array}{l}\text { Rated } \\
\text { Capacitance } \\
(\mathrm{PF})\end{array}$ & $\begin{array}{l}\text { Integral } \\
\text { insulation } \\
(\mathrm{M} \Omega)\end{array}$ & $\begin{array}{l}\text { Measuring } \\
\text { Capacitance } \\
(\mathrm{PF})\end{array}$ & $\begin{array}{l}\text { Dielectric } \\
\text { loss angle } \\
(\%)\end{array}$ & $\begin{array}{l}\text { Capacitance } \\
\text { difference } \\
(\%)\end{array}$ & $\begin{array}{l}\text { Tap insulation } \\
(\mathrm{M} \Omega)\end{array}$ & Result \\
\hline 1998.11 & 809.2 & 10000 & 809.2 & 0.18 & 0.00 & 10000 & Qualified \\
\hline 2008.5 & 809.2 & 10000 & 811.1 & 0.38 & 0.23 & 10000 & Qualified \\
\hline 2013.12 & 809.2 & 10000 & 804.1 & 0.43 & -0.63 & 10000 & Qualified \\
\hline
\end{tabular}

Table 2 All previous oil chromatographic tests data

\begin{tabular}{|c|c|c|c|c|c|c|c|c|}
\hline \multirow{2}{*}{ Date } & \multicolumn{7}{|c|}{ Component content (ppm) } \\
\cline { 2 - 9 } & $\mathrm{H}_{2}$ & $\mathrm{CH}_{4}$ & $\mathrm{C}_{2} \mathrm{H}_{6}$ & $\mathrm{C}_{2} \mathrm{H}_{4}$ & $\mathrm{C}_{2} \mathrm{H}_{2}$ & $\Sigma \mathrm{C}$ & $\mathrm{CO}$ & $\mathrm{CO}_{2}$ \\
\hline 1998.12 & 0 & 3.18 & 0 & 0 & 0 & 3.18 & 44.24 & 95.36 \\
\hline 2006.5 & 18.79 & 12.4 & 3.8 & 0 & 0 & 16.1 & 52 & 623 \\
\hline 2007.5 & 26.88 & 14.33 & 0 & 0 & 0 & 14.33 & 116.17 & 1932.73 \\
\hline 2008.5 & 34.34 & 18.89 & 0 & 0 & 0 & 18.89 & 98.77 & 804.37 \\
\hline 2013.3 & 18.84 & 13.25 & 5.06 & 5.19 & 0 & 23.5 & 163.24 & 909.88 \\
\hline 2014.3 & 17.92 & 13.13 & 4.94 & 5.12 & 0 & 23.19 & 157.46 & 879.79 \\
\hline 2015.4 & 18.46 & 15.67 & 5.13 & 4.72 & 0 & 25.52 & 174.29 & 914.26 \\
\hline
\end{tabular}

\section{The condition of disintegration}

After the accident, the current transformer and the other two of A-phase and C-phase were returned to factory. Partial discharge test, dielectric Loss Test, chromatographic test and gas moisture test were carried on the current transformers of A-phase and C-phase before their disintegration, and the results showed that there was no abnormality.

(1) The condition of disintegration of B-phase current transformer

As the porcelain sleeve was blown to bits and the charred main capacitor was burnt, only the oil tank was disintegrated. After the disintegration, two fault points located at the primary winding were found. The internal structure diagram is shown in Figure 2, and the specific circumstances of the various parts are as follows. 


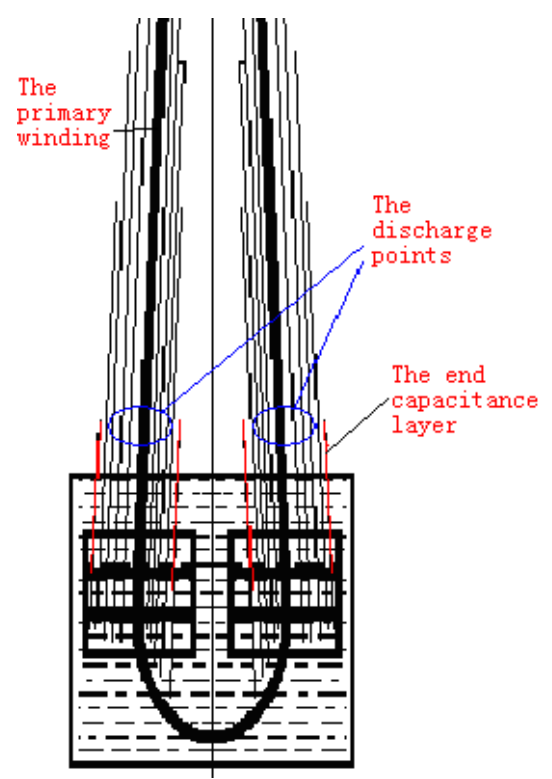

Fig.2 The internal structure diagram

1) The oil tank: No obvious discharge point was found inside, and the bottom surface and the lateral side of the tank were slightly arched for the tank was subjected to a great impact.

2) The expander: there was no mark that the expander was damped. The four oil boxes in series were all over flown, and the whole part failed to fall off.

3) The secondary windings: after separated out from the oil tank, the secondary windings were found burnt into black. There was no fault point found.

4) The terminal block of the secondary windings: the connection of secondary windings was good and there was no phenomenon of virtual connection and overheated.

5) The primary winding: the primary winding was a double winding constituted by two " $U$ " type aluminum pipes. There were two fault points found. The first one was at P1 side 100mm away from the top edge of the oil tank, and the combustion length was $100 \mathrm{~mm}$. The other one suspected as the first discharge point was at P2 side 150mm away from the top edge of the oil tank, and the combustion length was $100 \mathrm{~mm}$.

6) Tap of the end capacitance layer: only part of the insulating sheath was burnt, there was no broken strand in the copper wire, and the connection was good.

(2) The condition of disintegration of A-phase current transformer

As the oil level of this current transformer had reached the bottom line, internal lack of oil was suspected. After disintegration, it was found that there was no phenomenon of air entering or false Oil-Level though the oil level was relatively low. The primary winding, the main insulation, the capacitance layers and the connecting terminals were normal.

(3) Furfural test

Furfural content determination in the oil of C-phase current transformer was taken, and the result was $0.4 \mathrm{mg} / \mathrm{L}$. referring to DL/T 984-2005 "Guide for the diagnosis of insulation aging in oil-immersed power transformer", the condition was determined as moderate deterioration. The furfural test in the oil of the same time and the same type current transformer was also taken, and the result was well below $0.024 \mathrm{mg} / \mathrm{L}$, close to new oil standard. By comparison test, the furfural content was far higher than the one of other equipments.

\section{Test of power quality}

According to the information of this area power system, wind power generation is advancing rapidly these years. Because of the wind power integration, it has a suspicion that there is some harmonic component in the power of the substation. So, some days after the accident, some tests were taken in this substation and some surrounding ones, and every test lasts 36 hours continuously. 
It is found that the percentage of harmonic voltage and the flicker severity of this substation had exceeded the standard. It can be seen that the value of the 11th harmonic voltage and the 13th harmonic voltage were relatively high. And the time of the beyond-standard situation happened is approximately from 22:00 to 6:00 the next day, and the time of each day is almost the same. The harmonic voltage distortion rate measurement chart is shown in Figure 3, and the flicker measurement chart is shown in Figure 4.

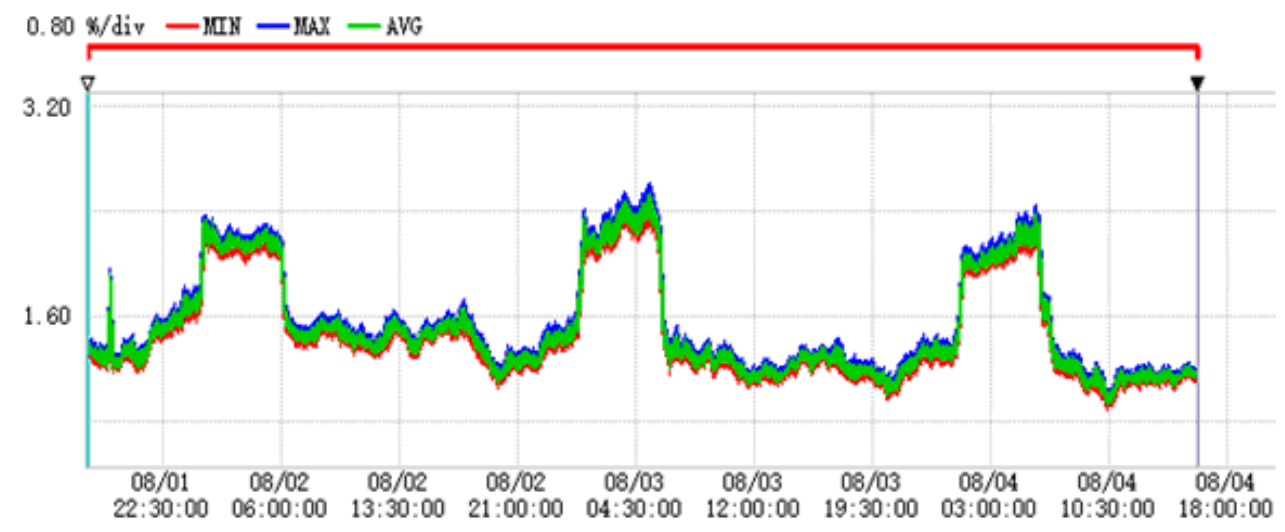

Fig.3 The harmonic voltage distortion rate measurement chart

It can be seen from Figure 3, the maximum harmonic voltage distortion rate had reached 2.63\%, the95\% probability value was $2.35 \%$, and these two values had exceed the limits of GB/T 14549-1993 “Quality of electric energy supply Harmonics in public supply network". At the same time, the beyond-standard situation had an obvious time period (from 22:00 to 6:00 the next day).

It can be seen from Figure 4, the maximum value of short time flicker had reached 4.09, the maximum value of long time flicker was 1.78, and these two values had exceed the limits of GB/T 12326-2008 "Power quality - Voltage fluctuation and flicker". At the same time, the beyond-standard situation had an obvious time period (from 22:00 to 6:00 the next day).

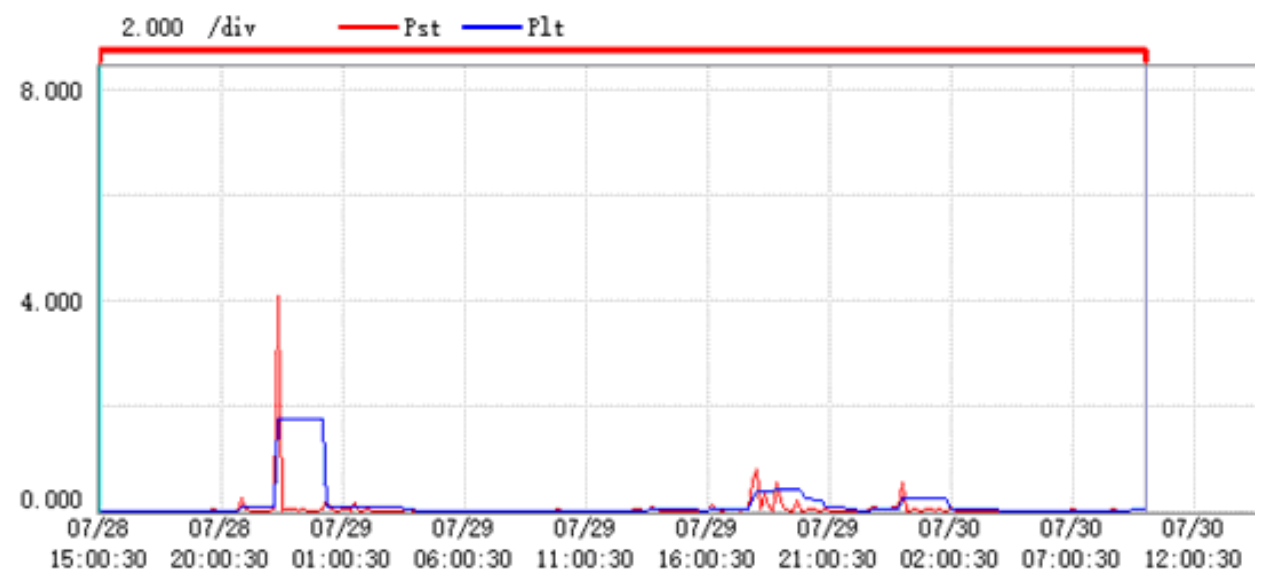

Fig.4 The flicker measurement chart

Through more detailed data analysis, it can draw a conclusion that the source of the harmonic voltage and the flicker is low-pressure side $(66 \mathrm{kV})$ of the $220 \mathrm{kV}$ transformer, so the influence of wind power can be excluded. According to this situation, a comprehensive inspection of harmonic voltage and flicker of $66 \mathrm{kV}$ lines in this substation and $10 \mathrm{kV}$ lines in subordinate substations was taken. On the basis of the result, it is known that the beyond-standard situation of each day is not identical. So, it demonstrates that the beyond-standard situation is generated by an unstable load. It is finally found that the sources are some $10 \mathrm{kV}$ large load customers supplied by the subordinate substation.

In conclusion, there were beyond-standard phenomena of the total distortion rate of harmonic voltage and the flicker severity in both of the $220 \mathrm{kV}$ side and the $66 \mathrm{kV}$ side of the transformer, and the time characteristic was obvious. 


\section{Reasons for accident}

According to the test results, combined with the operating conditions of the fault equipment, the causes are as follows.

(1) Under the action of the high harmonic voltage for a long time, polarization loss of the paper/ oil insulation increased, and dielectric loss also increased, then the temperature rose, causing the main insulation slowly deteriorated finally. During the process, chemical reactions such as thermal cracking and oxidative cracking would happen to the paper insulation at this high temperature, leading to further decline in its electrical performance and mechanical properties.

(2) After the insulation strength reducing, the end capacitance layer where the electric field relatively concentrated became a weak part of the main insulation. Under the continuous flicker impact produced by impact loads such as forging, smelting and machining, discharge phenomena happened at the end capacitance layer, and then tremendous energy produced, leading to explosion and fire.

In conclusion, reducing in main insulation electrical strength caused by Long-term high harmonic voltage and main insulation breakdown caused by flicker impact are the main reasons of the accident.

\section{Preventive measures of such accidents}

(1) Strengthen harmonic management of power system

Carry out the survey of the harmonic load of $220 \mathrm{kV}$ substations, monitor the harmonic output point of the loads which may produce harmonics, and govern the loads whose harmonics and flicker exceed standards.

(2) Strengthen inspection and maintenance of equipment

Carry out the infrared temperature measurement of transformers and other equipments, and strengthen the transformer oil level monitoring and expander appearance inspection.

\section{Reference}

[1] Pan Ling, Lu Jun, Lu Yuhang, Wang Zheng. The Analysis of 220kV CT Explosion Fault. Hydropower Automation and Dam Monitoring, 2014

[2] Yin Chen, Lin Yuhuang. Analysis for Causes of Fault for End-shield of Capacitance Equipment and the Preventive Measures. FUJIAN Electric Power And Electrical Engineering, 2007

[3] Zhou Guowei, Wu Shengli. The Harm of Harmonic in the Power Grid and the Method of Restraining the Harmonics. POWER CAPACITOR, 2006

[4] Shao Zhenguo, Wu Danyue, Xue Yusheng. Some Issues on the Flicker Source Location. High Voltage Engineering, 2009

[5] Chen Huagang. Electrical equipment preventive test method. Hydraulic and electric power press, 1999 